\title{
Correspondence
}

\section{Thyroid disorders in systemic lupus erythematosus are associated with secondary Sjögren's syndrome}

SIR, We read with interest the article by Goh and Wang on thyroid disorders in SLE.'

In a recent study of symptomatic secondary Sjögren's syndrome in SLE we systematically investigated 66 patients, ${ }^{2}$ who represented all diagnosed cases of SLE within a defined population. ${ }^{3}$ This study also included investigation of endocrine disease, including thyroid disorders. We found eight women with thyroid disease $(12 \%)$, including two patients with thyrotoxicosis, one with hypothyroidism, and five with non-toxic goitre. Definite evidence of autoimmune thyroid disease was lacking in the last group of patients, but one patient had a past history of a probable subacute thyroiditis, and another had a biopsy showing lymphocytic infiltration. In five cases thyroid disease appeared before the diagnosis of SLE. These findings are in accordance with the results of Goh and Wang, but in addition we found a strong association between secondary Sjögren's syndrome and thyroid disorders, not reported in their study.

Thirteen patients had chronic secondary Sjögren's syndrome, and within this group we found seven out of the eight cases of thyroid disease. The eighth patient had a history of mouth dryness and parotid enlargement but was

Table 1 Cumulative clinical and immunological findings in unselected SLE patients with thyroid disease (percentages)

\begin{tabular}{lcl}
\hline & $\begin{array}{l}\text { Thyroid disease } \\
(n=8)\end{array}$ & $\begin{array}{l}\text { No thyroid } \\
\text { disease } \\
(n=58)\end{array}$ \\
\hline Secondary Sjögren's syndrome & 88 & $10^{*}$ \\
Arthritis & 100 & 97 \\
Cutaneous & 100 & 69 \\
Serositis & 50 & 66 \\
Haematological & 50 & 33 \\
Renal & 25 & 29 \\
Neuropsychiatric & 25 & 38 \\
Anti-DNA & & 66 \\
Anti-RNP & 50 & 21 \\
Anti-Sm & 13 & 12 \\
Anti-SSA & 13 & 41 \\
Anti-SSB & 75 & 19 \\
Waaler-Rose & 50 & 9 \\
\hline
\end{tabular}

${ }^{*} \mathrm{p}<0 \cdot 001, \chi^{2}$. asymptomatic at the time of the study and was not considered to have chronic secondary Sjögren's syndrome.

Clinical and immunological findings are listed in Table 1.

The low numbers preclude firm conclusions, but the high frequency of cutaneous involvement is interesting in view of a similar finding by Goh and Wang. We found a correlation between anti-SSA autoantibodies and Sjögren's syndrome, but this association might be less marked with thyroid disorders.

Thus our findings support the observation that thyroid disorders are common in SLE. We observed a strong association between secondary Sjögren's syndrome and thyroid disorders in SLE, that might have pathogenetic implications.

Department of Rheumatology,

HELGI JONSSON

University Hospital,

OLA NIVED

S-221 85 Lund,

GUNNAR STURFELT

Sweden

\section{References}

1 Goh L. Wang F. Thyroid disorders in systemic lupus erythematosus. Ann Rheum Dis 1986: 45: 579-83.

2 Jonsson H. Nived O. Sturfelt G. Norberg R. Symptomatic secondary Sjögren's syndrome in patients with systemic lupus erythematosus (SLE). Relation to anti-SS-A and anti-SS-B autoantibodics. Scand J Rheumatol /Suppl/ (in press).

3 Nived O. Sturfelt G. Wollheim F A. Systemic lupus erythematosus in an adult population in southern Sweden. Incidence. prevalence and validity of ARA revised classification criteria. Brit J Rheumatol 1985: 24: 147-54.

\section{Serum ferritin: an indicator of iron responsive anaemia in patients with RA?}

SiR, The study of Hansen and Hansen presents data which. the authors conclude, indicate the need for iron therapy in anaemic patients with serum ferritin concentrations of $<60$ $\mu \mathrm{g} / \mathrm{l}$.' Our analysis of their data points to the opposite conclusion.

The anaemic patients in the study were a mixture of those who were frankly iron deficient (ferritin $<15 \mu \mathrm{g} / \mathrm{l}$ ) and those who were not. The iron deficient patients would be expected to respond to iron therapy with a marked change in haemoglobin concentration. This was the case in three of the five women and both men. When the iron deficient patients were excluded from the analysis, only six of the 10 women and two of the 10 men showed an increase in their haemoglobin concentration of $>8 \mathrm{~g} / \mathrm{l}$ after oral iron therapy. The changes in haemoglobin concentration in these patients were not correlated with any change in iron stores as reflected by the serum ferritin concentration 
$\left(r_{s}=0 \cdot 088 ; N S\right)$. There was, however, a significant negative correlation between change in haemoglobin concentration and change in the erythrocyte sedimentation rate (ESR) between the two occasions $\left(r_{s}=0.534: p<0 \cdot 05\right)$. There was no such correlation with $C$ reactive protein (CRP), but there was a significant correlation between CRP changes and changes in serum ferritin levels in the patients as a whole $\left(r_{s}=0.677 ; p<0.05\right)$.

This study therefore showed that any improvement in haemoglobin concentration in patients with rheumatoid arthritis who have a serum ferritin concentration of $>15$ $\mu \mathrm{g} / \mathrm{l}$ is likely to be the result of the amelioration of the disease, in so far as that is reflected by the ESR. Iron therapy was not shown to have had any effect. It should be remembered, however, that any erythropoietic response to disease improvement will place extra demands upon the iron stores. If these are insufficient to meet the new requirements for increased haemoglobin synthesis, this response may be limited. In practice it might be reasonable to expect there to be stores equivalent to a serum ferritin concentration of $20 \mathrm{\mu g} / \mathrm{l}$ for every $10 \mathrm{~g} / \mathrm{l}$ haemoglobin deficit. ${ }^{2}$ Patients with iron stores less than this may in the future develop an iron imbalance, but simply having a serum ferritin of $<15-60 \mu \mathrm{g} / \mathrm{l}$ cannot be considered an indication of the present need for iron therapy.

Dept of Haematology.

University Hospital of Wales.

I CAVILI

Heath Park,

Cardiff CF4 $4 \mathrm{XN}$

\section{References}

1 Hansen T M. Hansen N E. Serum ferritin as an indicator of iron responsive anaemia in patients with rheumatoid arthritis. Ann Rheum Dis 1986: 45: 596-602.

2 Cavill I. Diagnostic methods. Clin Haematol 1982: 11: 259-74.

SIR, Serum ferritin acts as an acute phase reactant which is increased in inflammatory diseases like rheumatoid arthritis. It is therefore inappropriate to use $15 \mu \mathrm{g} / \mathrm{l}$ as the lower normal limit in rheumatoid arthritis. $\mathrm{We}^{1}$ and others ${ }^{2-4}$ have previously shown that a lower limit of about $60 \mathrm{ug} / \mathrm{l}$ can discriminate between the absence and presence of stainable iron in bone marrow.

Of the anaemic patients in our study, an increase in haemoglobin concentration was found in $5 / 6$ patients with serum ferritin below $15 \mu \mathrm{g} / \mathrm{l}$, in $13 / 17$ patients with serum ferritin between 15 and $60 \mu \mathrm{g} / \mathrm{l}$, and in $6 / 12$ patients with serum ferritin above $60 \mu \mathrm{g} / \mathrm{l}$. If only an increase in haemoglobin concentration of more than $8 \mathrm{~g} / \mathrm{l}$ is accepted. the trend is the same $(4 / 6,10 / 17$, and $4 / 12$ respectively).

If one accepts a decrease of some magnitude in ESR and CRP as an indicator of decreased disease activity. this could be shown in, respectively $1 / 3,1 / 11$, and $3 / 4$ patients from the three groups who showed an increase in haemoglobin. If anything. this supports our conclusion. since three out of four patients in the last group (the 'false positives'), who showed an increased haemoglobin, probably did so because of decreased disease activity, whereas that was found in only one patient in each of the other two groups.

Serum ferritin rose in almost all patients given three months' treatment with iron. Since serum ferritin also acts as an acute phase reactant we are not surprised that serun ferritin levels did not reflect haemoglobin concentrations The ultimate test would. of course, have been a bone marrow examination for iron. Short of this, it should be considered whether a decrease in serum transferrin can be taken as evidence of improved iron status. If this i accepted, it is of interest that serum transferrin decrease in $5 / 5$ and $10 / 13$ patients in the first two groups but in onlos $1 / 6$ in the group with serum ferritin $>60 \mu \mathrm{g} / \mathrm{l}$.

We did not conclude that all patients with serum ferritin. $<60 \mu \mathrm{g} / \mathrm{l}$ should be treated with iron. but we suggest that one should look for iron deficiency in anaemic patient\$ with rheumatoid arthritis when serum ferritin is $<60 \mu \mathrm{g} / \mathrm{I}_{\mathrm{N}}^{0}$ This is in agreement with the study of others. ${ }^{2}+$ Serum ferritin $<6() \mu \mathrm{g} / \mathrm{l}$ is a better indicator of iron deficiency tha usual blood tests like mean cell volume, mean corpusculaf haemoglobin concentration, serum iron, and serum transferrin.

Dept of Rheumatology. T M HANSEפ

Kong Christian X’s Hospital.

6300) Graasten.

Denmark

Dept of Medicine and Haematology.

Gentofte Hospital.

2900 Hellerup.

Denmark

\section{References}

1 Hansen T M. Hansen N E. Birgens H S. Holund B. Lorenzen b Serum ferritin and the assessment of iron deficiency i rheumatoid arthritis. Scand $J$ Rheumatol 1983: 12: 353-9.

2 Rajapakse C N A. Holt P J L. Perera B S. Diagnosis of trut iron deficiency in rhcumatoid arthritis. Ann Rheum I) is $198\left(\frac{9}{3}\right.$ 39: $596-7$.

3 Smith R J. Davis P. Thomsen A B R. Wadsworth L D. Fack $P$. Serum ferritin levels in the anaemia of rheumatoid arthritise J Rheumatol 1977: 4: 389-92.

4 Blake D R. Waterworth R F. Bacon P A. Assessment of iro stores in inflammation by assay of serum ferritin concentration Br Med J 1981: 283: 1147-8.

\section{Observations on the effects of phenylbutazone}

SIR. In a recent letter in the Annals Drs Moens and Moerrs described their 16 year experience in treating 1.5 patients suffering from severe osteoarthritis of the knee witf intra-articular injections of phenylbutazone.' The invest gators conclude with the statement that they were unable to find any previous report on this subject.

We reported our observations on the use and clinic effects of intra-articular phenylbutazone in the Journal of Laboratory and Clinical Medicine. ${ }^{2}$ We administered 87 intra-articular injections of phenylbutazone in a series $\mathbb{P}$ 33 patients, including 18 with rheumatoid arthritis, 11 wit osteoarthritis, and four with various allied conditions. $\$$ $20 \%$ solution of $1 \mathrm{~g}$ phenylbutazone with $1 \%$ lidocaine wa employed. The average injection dose varied from $3 \mathrm{ml}$ t8 $5 \mathrm{ml}$ of the solution. The interval between injections ranged from one to six weeks. with a usual period of twg 